\title{
O contexto no trabalho móvel: Uma discussão à luz do paradigma da ubiquidade
}

\author{
The context in mobile work: A discussion in light of the paradigm of \\ ubiquity
} \begin{abstract}
Resumo
A disseminação das Tecnologias de Informação Móveis e Sem Fio (TIMS) como os telefones celulares, notebooks, smartphones, redes de telefonia celular, e redes sem fio permitem novas formas de interação na sociedade. Este artigo tem como objetivo discutir o significado de contexto e sua influência no trabalho móvel, levando em consideração o paradigma da ubiquidade. Para esta discussão foi feita uma coleta de artigos científicos sobre contexto nos principais periódicos internacionais da área de Sistemas de Informação. Sob o ponto de vista fenomenológico, o contexto, portanto, é gerado pelo significado da interação social entre indivíduo e tecnologia. Este artigo traz indícios das implicações do entendimento do contexto nas organizações, aos indivíduos, desenvolvedores, bem como na relação indivíduo-tecnologia.
\end{abstract}

Kathiane Benedetti Corso ${ }^{\mathrm{I}}$ Henrique Mello Rodrigues de Freitas ${ }^{2}$ Ariel Behr ${ }^{3}$

Palavras-chave: Trabalho Móvel, Paradigma da Ubiquidade, Contexto.

\begin{abstract}
The spread of Wireless and Mobile Information Technology (WMIT) as mobile phones, notebooks, smartphones, cellular networks and wireless networks enable new forms of interaction in society. This article aims to discuss the significance of context and its influence on mobile work, considering the paradigm of ubiquity. For this discussion we collected scientific articles about context in major international journals in the field of Information Systems. From the phenomenological point of view, the context is generated by means of social interaction between individuals and technology. The article presents evidence of the implications of understanding the context in organizations, individuals, systems developers, and in the relationship between individual and technology.
\end{abstract}

Keyword: Mobile Work, Paradigm of Ubiquity, Context.

\footnotetext{
${ }^{1}$ kathi.corso@gmail.com, Brasil. Professora Adjunta da Universidade Federal do Pampa - UNIPAMPA. Doutoranda em Administração na Universidade Federal do Rio Grande do Sul - UFRGS. Rua Barão do Triunfo, s/n, Centro, CEP: $97573-$ 590 - Sant'Ana do Livramento, RS - Brasil.

2 hf@ea.ufrgs.br, Brasil. Professor Titular da Universidade Federal do Rio Grande do Sul - UFRGS. Doutor em Administração pela Universite Pierre Mendes France Ecole Superieure Des Affaires (França). Rua Washington Luís, 855 , Centro, CEP: 90010-460 - Porto Alegre, RS - Brasil.

3 behr.ariel@gmail.com, Brasil. Professor Assistente da Universidade Federal do Pampa - UNIPAMPA. Doutorando em Administração na Universidade Federal do Rio Grande do Sul - UFRGS. Rua Barão do Triunfo, s/n, Centro, CEP: $97573-$ 590 - Sant'Ana do Livramento, RS - Brasil.
}

Recebido em 30.10.2012

Aprovado em 02.04.2013

Revista Administração em Diálogo

ISSN 2178-0080

Programa de Estudos Pós-Graduados em Administração

Pontifícia Universidade Católica de São Paulo 


\section{Introdução}

O novo cenário organizacional, de desempenho de diversos papéis, de longas horas de trabalho, de exigências cada vez maiores por resultados, é apoiado em sua grande parte pelo uso de novas Tecnologias de Informação e Comunicação (TIC's). Conforme Castells (2005) o que caracteriza a atual revolução tecnológica não é a centralidade de conhecimento e informação, mas a aplicação desses conhecimentos e dessa informação para a geração de conhecimentos e de dispositivos de processamento e de comunicação da informação, em um ciclo de realimentação cumulativo entre a inovação e seu uso. Com a evolução destas tecnologias, novos caminhos para o acesso à informação emergiram e vêm se expandindo rapidamente desde o surgimento da Internet na década de 9o. Atualmente vive-se a disseminação das Tecnologias de Informação Móveis e Sem Fio (TIMS) as quais permitem novas formas de interação na sociedade. Devido à sua pervasividade e o uso intensivo, estas tecnologias têm mudado nosso modo de viver em praticamente todas as esferas da vida social (KAKIHARA e SORENSEN, 2OOI).

As Tecnologias de Informação Móveis caracterizam-se pela sua portabilidade, ou seja, o usuário pode carregá-la para qualquer lugar. Os dispositivos mais conhecidos são os telefones celulares, notebooks, agendas eletrônicas, smartphones (telefones inteligentes), e PDA (assistente pessoal digital). As Tecnologias de Informação Sem Fio são as que permitem o uso de dispositivos conectados a uma rede ou aparelho de comunicação sem fio, como as redes de telefonia celular, o infravermelho, a identificação por rádio frequência (RFID), wireless LAN (rede local sem fio) e wi-max (SACCOL e REINHARD, 2OOZ).

Uma Tecnologia Móvel atualmente muito utilizada são os smartphones, dispositivos que podem agregar web, computador pessoal, câmera digital, televisão, $\mathrm{MP}_{3}$ player, e, utilizando uma rede, acessam e-mails, sites, vídeos, jogos, softwares, rádios, revistas, jornais e redes sociais. Por meio do uso destes aparelhos, os sujeitos carregam consigo informações e documentos que antes ficavam "presos" a lugares fixos como o desktop. Assim, ficam aptos a carregar informações a qualquer lugar, acessar, editar, enviar, receber e falar com outros usuários. Lyytinen e Yoo (2002) asseveram que tais ferramentas, cada vez menores, integrando diversos conjuntos de informação (pessoal, 
organizacional, pública) possibilitam desta forma, acessar, manipular, e compartilhar a informação em movimento.

As TIMS se tornam cada vez mais populares nas mais diversas áreas de atividade, devido à sua simplicidade, funcionalidade, portabilidade e facilidade de utilização (MYERS et al., 2004). Apesar de certas restrições quanto a custo, disponibilidade, padrões universais e segurança, as Tecnologias de Informação Móveis e Sem Fio se propagam mundialmente e, da mesma forma, no mercado brasileiro (SACCOL e REINHARD, 2007). De acordo com Shambare, Rugimbana e Zhowa (20I2) o aparelho celular tem se tornado um ícone do século XXI, e em função das suas diversas funcionalidades como dispositivo para conversas, plataforma para redes sociais, organizador pessoal, e banco móvel, por exemplo, é também um importante acessório social. Ainda que em 20I3, segundo consultoria IDC, as vendas de tablets em nível mundial tenham diminuído, se comparado a 2012 (IDG NOW, 2OI4), há que se considerar que o tráfego de dados em aparelhos móveis (smartphones, tablets, notebooks) teve um crescimento expressivo no mundo (TECNOLOGIA TERRA, 2OI4).

No que tange ao uso no contexto organizacional, uma pesquisa sobre Gerenciamento de Dispositivos Móveis e Segurança, da Information Week Analytics (2OIO) afirma que 2i\% das empresas têm mais da metade de seus funcionários usando smartphones. Uma pesquisa realizada em 3700 empresas de todo o Brasil com mais de IO funcionários revelou que o acesso remoto ao sistema de computadores pelos funcionários atingiu $25 \%$ das empresas com computadores, o que representa um aumento de dez pontos percentuais em relação a 2006 (COMPUTER WORLD, 2OIO).

O uso destas tecnologias faz parte do cotidiano de muitas empresas, propiciando cada vez mais a mobilidade do indivíduo. Dessa forma, apóiam as atividades empresariais, via telefones e notebooks com acesso a internet, bem como redes sem fio, possibilitando acesso a dados e informações em qualquer lugar, em qualquer hora, em qualquer ferramenta. Nas organizações elas oferecem diversas possibilidades, tais como o provimento de comunicação móvel, suporte a trabalhadores móveis, serviços baseados em localização, suporte a serviços de emergência na área da saúde, militar e de segurança pública, entre outros (ZHANG e YUAN, 2002). Perry et al. (2OOI, p. 323) também contribuem nesse sentido, afirmando que: 
Os movimentos rápidos e acelerados em direção ao uso de tecnologias móveis tem cada vez mais fornecido pessoas e organizações com a habilidade para trabalhar longe do escritório e se mover. Os novos meios de trabalho proporcionados por estas tecnologias são frequentemente caracterizados em termos de acesso a informação e as pessoas, a qualquer hora e qualquer lugar.

Dessa forma, o uso de TIMS propicia que os indivíduos organizacionais exerçam o chamado Trabalho Móvel. Este pode ser definido como a possibilidade de um indivíduo executar suas tarefas em locomoção, a qualquer hora, em qualquer lugar, em qualquer contexto, por meio do uso de tecnologias móveis e sem fio (KLEINROCK, 200I; LYYTINEN e YOO, 2OO2; KAKIHARA e SORENSEN, 2OO2; ANDRIESSEN e VARTIAINEN, 2006; YUAN e ZHENG, 2009). Como asseguram Zheng e Yuan (2007) com o uso de uma variedade de ferramentas portáveis como telefones celulares, assistentes pessoais digitais (PDA's), e notebooks, os trabalhadores móveis podem comunicar-se e colaborar uns com os outros em qualquer lugar, a qualquer momento, em um ambiente móvel dinâmico.

Várias forças motrizes demonstram que este tipo de trabalho está rapidamente ganhando impulso no mundo da vida profissional, tais como a redução de custos e aumento dos lucros econômicos, e a maior necessidade e preferência dos trabalhadores por este tipo de trabalho (ANDRIESSEN e VARTIAINEN, 2006). Conforme Brasil Digital@Intel (2OIO) a quantidade de trabalhadores móveis cresce à taxa de 5,8\% ao ano. Segundo estimativa da Consultoria IDC para 20I3, era de que cerca de I,2 bilhão dos trabalhadores do mundo realizariam suas atribuições por meio de telefones celulares. A Consultoria estima que os países emergentes devem alavancar esse crescimento da utilização de telefones como terminais móveis para iniciativas profissionais.

Dessa forma, a relevância do tema Trabalho Móvel se dá pela atratividade que tem, seja para as empresas que dessa forma tornam-se mais flexíveis, efetivas e inovativas, mas que também enfrentam desafios ao gerenciar este tipo de trabalho, seja para os trabalhadores que preferem ambientes de trabalho dinâmicos ou uma integração mais flexível de vida privada e trabalho (ANDRIESSEN e VARTIAINEN, 20o6). O aprofundamento dos estudos nesta temática permitirá que gestores e pesquisadores repensem os modelos atuais de funcionamento das organizações, considerando o 
Trabalho Móvel como um novo tipo de arranjo, que merece atenção e especificidade em seu gerenciamento.

Assim, para compreender as necessidades do trabalhador móvel, que se vê cercado por múltiplas tarefas e recursos tecnológicos, é preciso um profundo entendimento da noção de contexto. Este conceito se faz importante, pois no paradigma da ubiquidade, as tecnologias tornam-se onipresentes, imbricadas no ambiente, praticamente invisíveis e são “conscientes ao contexto” (WEISER, I99I; WEISER et al., I999). Diante deste cenário, este artigo tem como objetivo discutir o significado de contexto e sua influência no trabalho móvel, levando em consideração o paradigma da ubiquidade.

O artigo está estruturado em seis seções, incluindo esta introdutória. Na seção seguinte é abordado o conceito de trabalho móvel. O paradigma da ubiquidade, destacando o cenário que envolve o trabalho móvel é apresentado na terceira seção, para então na quarta seção discutir o significado do contexto no paradigma da ubiquidade. A construção desta quarta seção se deu por meio de coleta de artigos científicos sobre contexto nos principais periódicos internacionais da área de Sistemas de Informação. Destaca-se que em periódicos e anais de congressos nacionais não foram encontrados artigos sobre contexto, com o foco que os autores buscavam (uso da tecnologia móvel). A discussão dos conceitos e o entrelaçamento dos mesmos são feitos na quinta seção do artigo. Por fim, são feitas as considerações finais, destacando as implicações do entendimento do conceito de contexto e sua influência no trabalho móvel à luz do paradigma da ubiquidade para trabalhadores móveis, gestores, desenvolvedores de sistemas e organizações.

\section{Entendendo o Trabalho Móvel}

O desenvolvimento das Tecnologias de Informação e Comunicação tem substancialmente mudado o panorama da computação organizacional, como asseguram Lyytinen e Yoo (2002). Nesse sentido, usuários destas tecnologias são beneficiados pela mobilidade que tais ferramentas propiciam. Conforme Kakihara e Sorensen (2002) o conceito de mobilidade não deve ser exclusivamente relacionado ao aspecto espacial, isto é, à questão geográfica de deslocamento corporal dos indivíduos que as TIMS oferecem, 
como comumente é abordado pela literatura. Os argumentos da maioria dos estudos são de que a importância da mobilidade, ou nomadismo, é claramente focada na característica corpórea do movimento humano, libertado das restrições geográficas devido às tecnologias de computação móvel e serviços, tais como telefones celulares e assistentes digitais pessoais (PDA’s) (KAKIHARA e SORENSEN, 2OOI). Assim, os autores expandem a perspectiva geográfica defendendo que as tecnologias móveis oportunizam novas dimensões à interação entre as pessoas, possibilitando a mobilidade espacial, temporal e contextual:

[...] “ser móvel” não é só uma questão das pessoas que viajam, mas, muito mais importante, relacionada à interação que elas desempenham - a maneira pela qual elas interagem umas com as outras em suas vidas sociais (KAKIHARA e SORENSEN, 2OO2, p.I).

Dessa forma, tais tecnologias propiciam que os indivíduos exerçam diferentes papéis sociais, a qualquer hora, e em qualquer lugar. Ao permitir ao indivíduo se comunicar a qualquer momento e em qualquer lugar, a mobilidade muda a forma de os seres humanos interagirem, afetando suas relações sociais, familiares, afetivas e profissionais. No âmbito profissional, são geradas novas formas de organização do trabalho, como o teletrabalho, o trabalho móvel, trabalho nômade, e o trabalho misto entre ações presenciais e a distância. Conforme Andriessen e Vartiainen (2006, p. 4) “as mudanças tecnológicas, particularmente os desenvolvimentos em tecnologias de informação e comunicação (TIC's) móveis e sem fio, criam possibilidades para trabalhar em qualquer lugar e momento".

Com o desenvolvimento e massificação das TIMS, atualmente, passou-se a chamar de móvel aquele tipo de trabalho cujas atividades são realizadas utilizando-se tecnologias de informação móveis e sem fio, as quais permitem, não só estar longe, à distância do local tradicional de trabalho, mas em movimento, em qualquer lugar. É nesse sentido que Vartiainen (2006, p. 14) define o Trabalho Móvel como "a possibilidade de um indivíduo executar suas tarefas em locomoção, a qualquer hora e/ou em qualquer lugar, com a ajuda das tecnologias com e sem-fio, de maneira flexível". De uma maneira mais específica e clara, o Trabalho Virtual Móvel implica: 
[...] o interesse pelos cenários que foram distribuídos fisicamente e pelas pessoas móveis que interagem por meio das infraestruturas digitais e ferramentas móveis para desempenhar suas tarefas em um contexto organizacional que tem uma estrutura e cultura orientada para a mobilidade (ANDRIESSEN e VARTIAINEN, 2006, p. 7).

Kristoffersen e Ljungberg (2000 apud KAKIHARA e SORENSEN, 2002) descrevem quatro modalidades distintas de trabalho móvel quanto à espacialidade: (i) andar: ou movimentar-se em algum local específico, por exemplo, dentro de um depósito ou diferentes prédios ou salas para ir ao encontro de pessoas ou para atender a um evento; (ii) visitar: despender tempo em outros locais que não somente o local que serve como base para o trabalho por períodos temporários; (iii) viajar: ir de um lugar ao outro por meio de veículos como avião, trem, carro, ônibus; (iv) trabalhar em movimento (wandering): implica mobilidade física e espacial à medida que o trabalho vai sendo realizado, como por exemplo, um operador de caminhões em uma transportadora.

Então, os trabalhadores são considerados móveis quando andam, viajam, visitam clientes e movimentam-se, devido à mobilidade habilitada e facilitada pelo uso das TIMS. Isto é, os trabalhadores móveis são aqueles indivíduos que trabalham em, e se movem entre, diferentes locais de trabalho (ANDRIESSEN e VARTIAINEN, 2006), utilizando computador e ferramentas de comunicação para acessar informação remota da sua casa, do local de trabalho, no trânsito, e do seu destino (KLEINROCK, 2OOI).

A típica força de trabalho móvel, que utiliza tecnologias e serviços móveis e se move fisicamente, inclui gerentes, vendedores, transportadores, trabalhadores de serviços de campo, de emergência e de cuidados com a saúde, auditores, consultores, patrulhamento policial dentre outros (ANDRIESSEN e VARTIAINEN, 20o6; YUAN e ZHENG, 2009). Segundo Yuan e Zheng (2009) é possível categorizar estes trabalhadores móveis em dois grupos: os trabalhadores móveis do conhecimento e os de campo. Trabalhadores móveis do conhecimento englobam gerentes, força de vendas, jornalistas, agentes de estado, guias turísticos, enquanto que os trabalhadores móveis de campo são empregados de centros de distribuição, entregadores de produtos e serviços, motoristas de táxi e caminhão, seguranças, e pessoal de emergência (polícia, bombeiros e ambulância). 
os trabalhadores móveis, de campo ou de conhecimento (KLEINROCK, 20oI; ANDRIESSEN e VARTIAINEN, 2006; YUAN e ZHENG, 2009) acessam, manipulam e compartilham informação em movimento (LYYTINEN e YOO, 2002), o que lhes proporciona mobilidade, tanto na esfera de espaço, tempo e contexto (KAKIHARA e SORENSEN, 2002), como esquematizado na Figura I:

Figura I: Trabalho Móvel

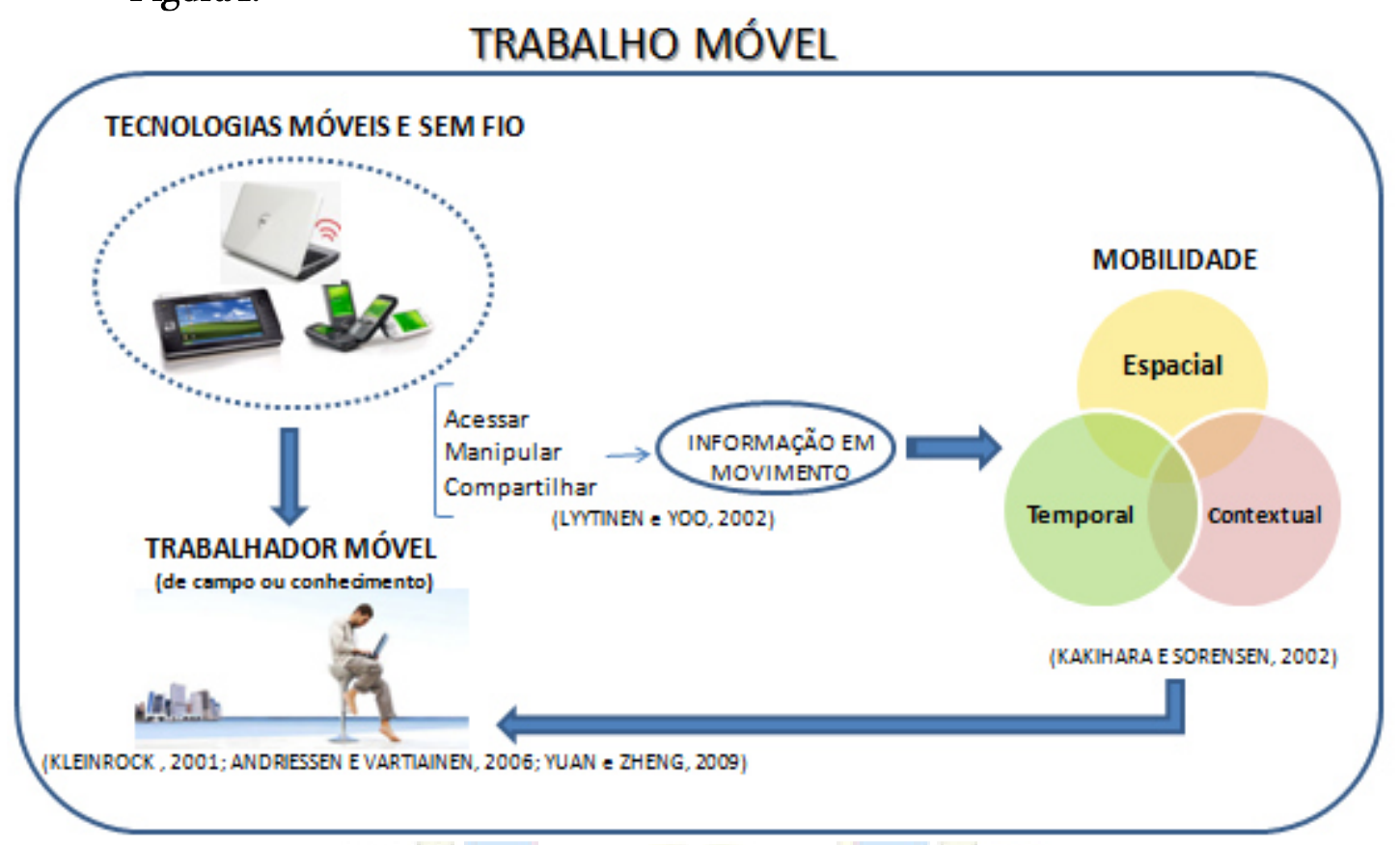

Fonte: Elaborada com base em Kleinrock (200I), Lyytinen e Yoo (2002), Kakihara e Sorensen (2002), Andriessen e Vartiainen (20o6) e Yuan e Zheng (2009)

Esta mobilidade, onde o indivíduo acessa a informação em qualquer lugar, a qualquer hora, independentemente do contexto que se encontra, quando em questões organizacionais, podemos chamar de Trabalho Móvel. Dado que este trabalho móvel efetua-se a luz do paradigma da ubiquidade, e haja vista as necessidades e as diversas tarefas e recursos tecnológicos que circundam o trabalhador móvel, a noção de contexto se faz relevante e requer uma profunda discussão.

\section{O Paradigma da Ubiquidade}

Um paradigma, na acepção de Freire-Maia (ı99ı, p. 43) é definido como um “conjunto de conceitos fundamentais que, num dado momento, determina o caráter da descoberta científica”, ou seja, orientam o encaminhamento das pesquisas. Os novos 
paradigmas nascem dos antigos, incorporando grande parte do conteúdo que o paradigma tradicional já empregava, seguindo um processo natural de evolução e substituição (KUHN, I982). Foi nesta sequência natural que o Paradigma da Ubiquidade emergiu nos anos 9o, sendo conhecido como a terceira onda da Computação. O desenvolvimento das TIMS, e o consequente trabalho móvel que se insere no paradigma da ubiquidade, foram evoluindo dentro de determinados paradigmas da computação.

A primeira onda ou paradigma se deu nas décadas de 6o e $7 \mathrm{O}$, quando do surgimento dos primeiros computadores, os chamados mainframes, em que se tinha um computador para ser utilizado por vários usuários. O segundo paradigma que vigorou entre os anos 80 e 90 foi o dos computadores pessoais, onde o usuário passa a ter um computador para seu próprio uso, ainda que em forma de desktop (WEISER et al., I999). A partir dos anos 9o, em decorrência do rápido avanço das tecnologias de informação móveis e sem fio, e do uso da internet, a Computação Ubíqua surge como novo paradigma, possibilitando que o usuário tenha diversos dispositivos de comunicação a sua disposição para interação, e estes se tornem praticamente invisíveis.

O Paradigma da Ubiquidade cunhado na década de go por Mark Weiser, integra elementos da ciência da computação, da engenharia, das ciências sociais e humanas. Em artigo seminal "The Computer for the 21st Century", Mark Weiser (I99I) descreveu o fenômeno da Computação Ubíqua como a integração contínua de computadores no mundo em que vivemos. Neste ambiente, Weiser previu que os computadores desapareceriam do nosso olhar, tornando-se comuns e pervasivos em vários aspectos de nossas atividades diárias, e passariam a fazer parte de todos os objetos, de forma integrada e onipresente. O pai deste novo paradigma vislumbrou naquela época que, no futuro, computadores habitariam os mais triviais objetos: etiquetas de roupas, xícaras de café, interruptores de luz, canetas, entre outros, de forma invisível para o usuário (WEISER, I99I).

Nesse contexto, Roussos (2006, p.I) corrobora que "o que diferencia a computação ubíqua dos paradigmas anteriores é o fato de que a capacidade da computação e das comunicações (wireless) está incorporada nos objetos, locais, e até mesmo nas pessoas”, sendo possível interagir livremente com os recursos digitais. Portanto, a Computação Ubíqua é um novo paradigma em que pequenos dispositivos 
computacionais distribuídos e integrados, alocados em ambientes, ou portáveis, fornecem serviços e informações a qualquer momento, em qualquer local. Estes serviços tendem a ser incorporados à vida cotidiana de forma que sua presença passa a ser despercebida, invisível, no sentido de ser utilizável sem qualquer esforço, usando linguagens comuns do dia-a-dia, como toque, fala, audição e pensamento, e não teclado e mouse.

Conforme Weiser (I99I, p.I) “as tecnologias mais profundas e duradouras são aquelas que desaparecem. Elas dissipam-se nas coisas do dia a dia até tornarem-se indistinguíveis." Nesse sentido, os usuários não se distraem com as tecnologias em si, mas sim, as utilizam inconscientemente na realização de suas tarefas. O Paradigma da Ubiquidade tem como objetivo embutir a computação no ambiente e em objetos de uso diário, de forma que as pessoas possam interagir com os dispositivos de forma natural, e estes estejam aptos a considerar diversos aspectos como, por exemplo, a localização e o ambiente onde os indivíduos se encontram.

Os conceitos que Weiser cunhou na década de 90 com relação à computação ubíqua, começam hoje a integrar as tecnologias que utilizamos no dia a dia, dado o desenvolvimento da Internet, a ampliação das opções de conexões, e a miniaturização dos dispositivos. Celulares com acesso à internet, notebooks, redes sem fio, lousas digitais, e smartphones, permitem aos usuários, sem perceberem, a utilização a qualquer momento e em qualquer lugar de um sistema de computação, através de um software e/ou de uma interface. Acrescentam-se a essas, as tecnologias de informação ubíquas propriamente ditas, ou seja, tecnologias sensíveis a diferentes contextos e atividades humanas que possibilitam a comunicação tanto pessoa-objetos quanto objeto-objeto (SACCOL e REINHARD, 2007). Roussos (2006) destaca como aplicações ubíquas a identificação automática por meio de tags RFID (Identificação por Rádio Frequência) que podem ser incorporados nos objetos ou pessoas; as redes de sensores que coletam informações do contexto via estímulos biológicos, químicos e mecânicos; e ainda, o sensoriamento local por meio de GPS (Sistema de Posicionamento Global).

O Paradigma da Ubiquidade, portanto, significa a onipresença da tecnologia nos espaços de atividade. Na prática, é quando o indivíduo está no escritório lendo seus emails em uma tela holográfica, e assim que sair do escritório, o que estava sendo 
apresentado anteriormente naquela sala poder ser transferido para seu smartphone, sem qualquer interação do usuário. Para que os sistemas móveis ubíquos e as tecnologias desapareçam é necessário que elas sejam “conscientes” do contexto, tornando-se parte dele. Uma das principais áreas de pesquisa dentro da computação ubíqua é a computação ciente do contexto (context-awareness computing), de tal modo, o conceito de Contexto é apresentado e discutido na seção seguinte.

\section{O significado do Contexto no Paradigma da Ubiquidade}

No Paradigma da Ubiquidade, a computação pode ser sensível e responder ao cenário em que está sendo explorada e utilizada. De tal modo, este paradigma traz um desafio para a área de pesquisa da Interação Homem-Computação (IHC) e consequentemente para o trabalho móvel: o entendimento do contexto. Dourish (2004, p.2) discute o significado de contexto, afirmando que "uma preocupação primária da pesquisa em computação ubíqua é entender a relação potencial entre a computação e o contexto em que esta está incorporada”.

O contexto é utilizado geralmente com dois diferentes significados nos sistemas de computação ubíqua, podendo ser entendido à luz das perspectivas social e técnica. Dourish (2004) nos mostra então que para compreender o contexto sob estas duas perspectivas requer entendê-las dentro de dois frames intelectuais que lhes dão significado: o Positivismo para a visão técnica e a Fenomenologia para a visão social.

As teorias Positivistas buscam reduzir os fenômenos sociais observados a essências ou modelos simplificados que capturam os padrões subjacentes (DOURISH, 2004). Dessa forma, o autor define o contexto sob a ótica positivista, como um problema de representação, isto é, questiona como o contexto pode ser codificado e representado pelos sistemas. Os conceitos trazidos por Dourish (2004) evidenciam que contexto à luz desta lente de análise diz respeito a tudo aquilo que representa o cenário, o ambiente de uso dos sistemas ubíquos: "local, identidade, ambiente, e tempo" (RYAN et al., I997); "qualquer informação que pode ser usada para caracterizar a situação das entidades" (DEY et al., 20OI); e ainda, "inclui iluminação, nível de barulho, conectividade de rede, custos de comunicação e a situação social” (SCHILIT et al., I994).

Nessa perspectiva são quatro as suposições que Dourish (2004) diz sustentar a 
noção de contexto: (a) Contexto é uma forma de informação: é alguma coisa que pode ser conhecida, codificada e representada em sistemas de software; (b) Contexto é delineável: podem-se definir as necessidades das atividades que as aplicações apoiam; (c) Contexto é estável: embora os elementos de um contexto possam variar de aplicação para aplicação, elas não variam de instância para instância de atividade ou evento; e (d) Contexto $e$ atividade são separáveis: o contexto descreve características de um ambiente que contém uma atividade. Destaca-se que a maioria das pesquisas em computação ubíqua embasa a noção de contexto sob estas quatro perspectivas, demonstrando que este consiste em um conjunto de características do ambiente circundante às atividades, e que estas características podem ser codificadas e disponibilizadas por sistemas.

Por outro lado, as teorias Fenomenológicas consideram os fatos sociais como propriedades emergentes de interações, que não são previamente dadas, mas sim negociadas e contestadas, e subjacentes aos processos de interpretação e reinterpretação (DOURISH, 2004). Assim, o contexto sob a ótica fenomenológica, é apresentado pelo autor como um problema de interpretação, ou seja, demonstra a preocupação com o que realmente é o contexto e como ele pode ser codificado. No modelo interacional de contexto que Dourish $(2004$, p. 6) busca propor, “o contexto não é somente algo que descreve um cenário, é alguma coisa que as pessoas fazem. É uma realização, ao invés de uma observação, um resultado ao invés de uma premissa”.

Discordando das suposições que sustentam a noção de contexto positivista, Dourish (2004) defende que na ótica fenomenológica: (a) Contextualidade é uma propriedade relacional mantida entre objetos e atividades, em que algo pode ou não ser contextualmente relevante; (b) O escopo das características contextuais é definido dinamicamente, e não delineado e definido antecipadamente; (c) Contexto é uma propriedade ocasionada, particular para cada cenário, atividade e instância de ação; e (d) Contexto surge de uma atividade, é ativamente produzido, mantido e desempenhado no curso de uma atividade, logo não podem ser separados.

Ao arguir que o contexto é uma característica de interação, e que a principal preocupação dos sistemas baseados no contexto é em usar o contexto para elaborar o significado de uma atividade do usuário, Dourish (2004) busca ligar os conceitos de ação e significado ao conceito de “prática”. O autor cita Wenger (I998) o qual afirma que Revista Administração em Diálogo ISSN 2178-0080 
"Prática [...] é um processo em que nós podemos experienciar o mundo e nosso engajamento com ele é significativo". A prática não é meramente sobre o que as pessoas fazem, mas sobre o que elas experienciam ao fazer. Portanto, o que é crucial para a visão interacional de contexto é ver a prática como um processo dinâmico, que envolve e adapta (DOURISH, 2004). O contexto emerge nas práticas e significados que os atores dão na sua interação com os sistemas ubíquos. Em outras palavras, o contexto é então o modo em que as ações que executamos têm significado, e tudo aquilo que emerge diante desta experiência, podendo ser novas formas de ação e significado.

Visto pela tradição da técnica positivista o contexto diz respeito às coisas estáticas, às características do cenário, e não depende da ação dos indivíduos, da interação entre as partes como na ótica social fenomenológica. O entendimento do contexto sob este prisma, que defende a agregação das experiências e resultados das práticas incorporadas no uso da tecnologia, permite uma compreensão mais profunda da interação homem-computação em ambientes ubíquos. Como Dourish (2004) assevera, parte do que as pessoas fazem quando adotam e adaptam tecnologias, incorporando-as em seu próprio trabalho, é criar e comunicar novos significados por meio do uso daquelas tecnologias. Dessa forma, a discussão trazida pelo autor conduz a uma reconsideração do papel humano e do agente tecnológico no desenho de sistemas ubíquos e interativos, e demonstra a preocupação em como a tecnologia é utilizada e incorporada nas práticas.

Os dispositivos e serviços móveis precisam de consciência de vários fatores contextuais, incluindo fatores sociais, psicológicos e físicos, logo a interpretação dos mesmos e como devem ser atendidos são questões que merecem atenção (TAMMINEM et al., 2004). A fim de entender os ambientes urbanos móveis de computação consciente ao contexto, Tamminem et al. (2004) realizaram um estudo empírico com abordagem centrada no usuário por meio de uma etnografia com 25 cidadãos de Helsinki na Finlândia. Seu objetivo não foi discutir precisamente o significado de contexto, mas como os diferentes aspectos de contexto móvel são criados e mantidos pelas ações situadas na vida cotidiana.

Os autores defendem que "contextos são sempre determinados por situações de uso específico carregados com diferentes recursos de ação: motivos, planos, outras 
pessoas, computadores móveis, e semelhantes" (TAMMINEN et al., 2004, p. I36), e assim, dão atenção em especial no estudo à natureza interacional e situada dos contextos móveis. Visto que as atividades móveis requerem mudanças constantes de contexto, ou de navegação, como os autores descrevem, a preocupação se dá no sentido de entender como as interações dos indivíduos com outras pessoas, com a tecnologia disponível e com o exterior circundante de suas ações criam e acolhem os contextos móveis.

O convívio dos pesquisadores, por meio de observação participante durante alguns dias com os indivíduos de variadas profissões em suas atividades cotidianas na área metropolitana permitiu identificar cinco características dos contextos móveis: situação, espaços pessoais e de grupo, navegação, tensão temporal e multi-tarefa. Estas podem ser vistas como a soma de diferentes recursos e ações pelas quais os contextos são construídos e apoiados.

A primeira característica, dos atos situacionais planejados, diz respeito ao fato de que, geralmente as pessoas têm um plano mental de como vão navegar de um local para outro - entende-se deslocar-se - e que ações vão desempenhar em determinado plano. Porém, muitas ações são inesperadas durante as jornadas, sendo situações ad hoc, momentâneas para aquela situação. Assim, durante a navegação do indivíduo, surgem mudanças de contexto não planejadas que conduzem a atos situacionais não planejados (TAMMINEN et al., 2004).

Os autores elencam a reivindicação por espaços pessoais e de grupo como outra característica do contexto móvel, derivada da necessidade natural e universal que as pessoas têm desses espaços. São estes espaços que constituem e indicam a natureza da interação social a ser realizada em dada situação. Dessa forma, as pessoas regulam seu envolvimento nessas interações com diferentes recursos situacionais, como por exemplo, o afastamento do grupo, quando da necessidade de uma conversa em particular. Espaços territoriais, individuais ou de grupo, são necessários, e vão delinear o contexto, a interação, e ação e os recursos utilizados.

Tamminem et al. (2004) abordam a navegação em espaços urbanos como uma dificuldade que os indivíduos encontram devido às distâncias de um lugar ao outro, rotas de difícil acesso, entre outros. Porém, indicam que estes problemas podem ser resolvidos pela interação dos indivíduos que se deslocam, com outras pessoas, estabelecendo 
formas de canais sociais. Esta interação propiciará, mas também requererá uma renegociação da próxima ação de navegação e da agenda compartilhada, quando outras pessoas estiverem envolvidas naquele plano previamente estabelecido.

As tensões temporais são outra característica dos contextos móveis, e remetem as flutuações de tempo e espaço como fatores contextuais. Estas tensões são situações onde o tempo torna-se problemático em relação à ação, e onde, ao mesmo tempo, o aspecto temporal da situação é ativamente utilizado para orientar a ação (TAMMINEM ET AL., 2004). Estas tensões podem se dar em quatro estágios: aceleração, processo normal de antecipação, abrandamento e parada. Assim, as diversas tarefas podem ser desempenhadas mais ou menos simultaneamente, de forma que o indivíduo execute ações em estados de aceleração, pressa, desaceleração, normal ou de espera.

O deslocamento pelos diferentes ambientes requer uma constante atenção com os arredores, mas esta atenção que as pessoas dão aos recursos disponíveis para interagir é limitada. Tamminem et al. (2004) apresentam a característica da multitarefa, remetendo ao fato das pessoas estarem constantemente se posicionando e reposicionando no contexto social de outras pessoas e objetos devido as suas diversas tarefas a desempenhar. Dessa forma, deslocar-se com atenção ao ambiente desenvolvendo multi-tarefas pode vir a dificultar o plano de navegação e ação.

Os autores reforçam a importância de reconsiderar o papel do contexto nos estudos de tecnologia e ação humana, e isto envolve um olhar sobre as ações situadas dos indivíduos que desenvolvem suas atividades em ambientes móveis. Os resultados do estudo apresentaram as restrições psicológicas e de interação social na mobilidade, isto é, como atos planejados e situacionais intervêm na navegação, como pessoas constroem espaços pessoais e de grupos, e como as tensões temporais desenvolvem-se e dissolvemse.

Outra contribuição para o entendimento de contexto é a de Ciborra (2006), que esclarece as diferenças entre ação situada, contexto, situação, e situacionalidade. O autor aprofunda o conceito de contexto ao discutir ao trazer o conceito de situacionalidade (situatedness), criticando o seu limitado significado que é empregado em grande parte dos estudos organizacionais. A origem da palavra situatedness vem do alemão "befindlichkeit", que na visão fenomenológica de Heidegger (I962) refere-se não 
somente ao "estado mental" do ator e às circunstâncias encontradas, mas também à sua disposição, humor, afetividade e emoção, ou seja, à sua "situação interna”, ao indivíduo como um todo (CIBORRA, 2Oo6). Porém, grande parte dos estudos contemporâneos que utiliza o termo situacionalidade, ainda que com um olhar fenomenológico, acaba por utilizar o mesmo superficialmente, significando na maioria das vezes "contexto" ou “circunstâncias emergentes” de ação e conhecimento.

Como exemplo do uso contemporâneo da definição de situacionalidade Ciborra (2006) traz os conceitos de ação situada de Suchman (I987) que a define como: "ações tidas em um contexto particular, circunstâncias concretas [...] as circunstâncias de nossas ações nunca são totalmente antecipadas [...] são essencialmente $a d$ hoc”. Logo, para Suchman (1987) as ações não são planos, mas "locais de interações com o nosso ambiente”, sendo o mundo um inesgotável e rico meio para a ação. Nesse sentido, Ciborra (2006) afirma que a definição de ação situada utilizada em diversos estudos permite um olhar de como os sistemas podem lidar com o reconhecimento das circunstâncias locais. Ainda, possibilita perceber e representar as relações sociais, se elas têm um impacto no sistema e produzem respostas apropriadas mesmo para tarefas temporalmente demandadas em ambientes complexos.

Nos casos apresentados, Ciborra (2006) constata que os estudos com abordagens interpretativistas utilizadas nos estudos contemporâneos sociais e organizacionais têm transformado a noção original de situacionalidade de Heidegger em noções de mudança situada (Orlikowski, I996), conhecimento situado (Haraway, I99I), aprendizagem situada (Lave e Wenger, I99I) e ação situada (Suchman, I987). O conceito de "befindlichkeit" "busca capturar uma multiplicidade de significados do ser em uma (simultaneamente interna e externa) situação" (CIBORRA, 2006, p. I38), o que não se encontra nestes estudos, que deixam de analisar o indivíduo como um todo, estudando separadamente o observado e a situação em questão. A visão de Heidegger da noção de situação inclui abordar todos os momentos da vida interna do ator, sua mente e coração. Nesta perspectiva, qualquer forma de entendimento é situado, ou seja, afetado, demonstrando a situacionalidade do indivíduo no mundo. Esta perspectiva desafia a articulação da situacionalidade na análise organizacional com o desenvolvimento de sistemas interativos. 
Por fim, é relevante discutir questões que tangenciam o entendimento de contexto, como a interação ubíqua. Ao constatar que existem poucas pesquisas focando no entendimento das experiências dos usuários de computação ubíqua na vida real, Sorensen (2OIO) aborda em seu estudo o contínuo cultivo do usuário da interação ubíqua, ou seja, a organização contínua da interação mediada para se adequar às necessidades e preferências. Quando o usuário se engaja com a tecnologia em um processo de interação por meio de TI móvel, não é garantida a relação harmoniosa entre ambos, como já previa Weiser, visto que a tecnologia apoiará o usuário, mas também vai impor demandas a ele (SORENSEN, 2OIO). Assim, entender a relação entre as possibilidades tecnológicas (affordances) e a atividade humana torna-se um desafio.

Combinando então dois conjuntos de suposições sobre a diversidade das possibilidades para a ação apoiada na tecnologia, quatro são os tipos de possibilidades resultantes, que apresentam um tipo característico de apoio tecnológico incorporado para cultivar a interação ubíqua dos usuários. São eles: Conectores, Filtradores, Coordenadores e Mediadores, os quais variam de acordo com as características da interação, se de encontro ou relacionamento e, se assimétrica ou simétrica.

O autor destaca a interação ubíqua como um aspecto particular quando se aborda a relação entre indivíduo e possibilidades tecnológicas oferecidas. A experiência de ubiquidade do usuário é complexa e uma propriedade emergente de situação, sendo moldada por uma variedade de fatores que englobam assuntos práticos de tecnologia, situação, e questões fundamentais do estado emocional da pessoa (SORENSEN, 2OIO).

Assim, a interação ubíqua caracteriza o usuário experienciando uma relação simbiótica com a tecnologia de apoio em sua interação com indivíduos remotos, grupos ou sistemas interativos. Na situação de trabalho, o cultivo desta interação requer coordenar múltiplos interesses do usuário como indivíduo, membros de equipe, e o restante da organização.

A análise de quatro estudos de caso apresentados por Sorensen (2OIO) mostra que a interação ubíqua no trabalho foi organizada por meio da diversidade das possibilidades (affordances) da tecnologia. O autor assegura que existe uma necessidade de refletir sobre as consequências das escolhas tecnológicas feitas pelo usuário, uma vez que esse engajamento acarreta em um processo de apropriação social. Dessa forma, estas 
escolhas implicam aos indivíduos conseqüências sócio técnicas na interação que irão ter com a tecnologia.

\section{Entrelaçando conceitos: o Contexto em ambientes ubíquos de Trabalho Móvel}

Coutaz et al. (2005) afirmam que desde os anos 60 a noção de contexto tem sido modelada e explorada em muitas áreas da informática. A comunidade científica tem debatido suas definições e usos por longos anos, mas não alcançou um consenso claro. Conforme podemos constatar em Dourish (2004), não existe uma única definição para contexto, e sim entendimentos conforme a visão paradigmática que se tem, se Positivista (perspectiva técnica) ou Fenomenológica (perspectiva social). Nesta seção, a discussão recai sob a visão Fenomenológica, a fim de entrelaçar os conceitos discutidos até então sobre contexto em ambientes ubíquos e trabalho móvel.

A abordagem de contexto do ponto de vista fenomenológico é trazida na discussão de Dourish (2004) e Tamminem et al. (2004), visto que para ambos contexto é algo que as pessoas fazem, é uma ação. Dourish (2004) contribui com seu conceito de interação e de significado, ao definir que o contexto emerge das práticas e significados que os atores dão às suas ações quando estão em interação. Para ele um contexto é então tudo aquilo que emerge dos significados das experiências e das ações que temos em nossas atividades. A contribuição de Tamminem et al. (2004) é a de assegurar que os contextos são criados e mantidos pelas ações situadas, ou seja, o contexto se dá em função das situações de uso específico, em que atos situacionais, espaços pessoais e de grupo, navegação, tensões temporais e as multi-tarefas vão ser levados em conta.

Enfim, para estes autores o contexto é definido dinamicamente, e vai emergir das atividades executadas pelo indivíduo. Tamminem et al. (2004) e Dourish (2004) convergem no sentido de que o contexto é fortemente imbricado com as interpretações internas e sociais dos usuários, em continua mudança. Dessa forma, se torna difícil capturar o contexto de qualquer modo que possa apoiar o desenvolvimento de sistemas ubíquos (TAMMINEM ET AL., 2004). Logo, entender o contexto implica em levar em conta aspectos de interpretação da interação em diferentes momentos.

É possível perceber uma crítica dos autores (TAMMINEM et. al, 2004; DOURISH, 2004) à visão positivista e técnica de contexto da maioria das pesquisas que 
vem sendo desenvolvidas, como bem destacado por Ciborra (2006). Grande parte dos estudos empíricos preocupa-se com contextos fixos, estáticos, identificando os mesmos como um escritório, uma sala de reuniões (TAMMINEM et al., 2004), ou seja, um determinado cenário onde uma atividade é desempenhada, ficando a parte do contexto, ou até mesmo ignorado a ação do usuário.

O estudo de Sorensen (20Io) embora não aborde diretamente o conceito de contexto contribui para seu entendimento ao destacar a interação ubíqua, aquela experiência entre usuário e tecnologia. Nesse sentido, aproxima-se do conceito de ação situada de Tamminem et al. (2004) ao afirmar que a experiência ubíqua depende da situação, destacando as diferentes possibilidades de uso da tecnologia, visto que elas também vão influenciar o tipo de interação. Assim, estas possibilidades também vão afetar a interação, dando um significado para o contexto.

Apesar de trazerem uma visão fenomenológica para o entendimento de contexto tanto Dourish (2004) como Tamminem et al. (2004) não abordam aspectos da vida interna do usuário na interação com a tecnologia, como é trazido por Ciborra (2006), quando retoma o significado dado por Heidegger de situacionalidade. Ciborra (2006) busca clarear a confusão que muitas vezes se faz nos estudos entre situacionalidade e ação situada, contexto ou situação. A situacionalidade resgatada pelo autor, busca na origem de seu conceito, a captura de uma diversidade de significados, ou seja, dimensões não cognitivas da situação, em particular a situação do ator em determinado momento, suas emoções, estado de espírito, humor, disposição. Ciborra (2006) nos permite então ver este indivíduo, usuário de tecnologia e que com ela interage, como um todo.

Se no Paradigma da Ubiquidade a computação sensível e consciente ao contexto busca responder ao cenário de interação constituída, então a definição de contexto a ser adotada vai ter extrema importância na análise a ser feita. Na tentativa de elaborar um framework de pesquisa, escolheu-se a perspectiva Fenomenológica de contexto abordada até então, para ilustrar o entendimento do mesmo. Esta escolha se dá em função da visão Positivista ser limitada, visto que cita um conjunto de características, e afirma que as mesmas delineiam um contexto, e o fato de o contexto como forma de representação ter sido muito estudado até então (SORENSEN, 2OIO), enquanto que pouca atenção vem sendo dada ao contexto como interação. 
A Figura 2 busca elucidar o entendimento de contexto no Paradigma da Ubiquidade à luz da perspectiva social fenomenológica. Como visto na discussão anterior, o contexto não é estático, e sim constituído por meio da interação, que é definida e mantida por uma determinada ação (DOURISH, 2004). Assim, indivíduo e tecnologia estabelecem uma interação ubíqua (SORENSEN, 2OIO) que é caracterizada por uma ação situada (TAMMINEM et al., 2005) em função das situações de uso específico. Esta ação é influenciada, conforme Tamminem et al. (2005) por atos situacionais, espaços pessoais e de grupo, navegação, tensões temporais e as multi-tarefas, elementos que por si só caracterizam o ambiente ubíquo de trabalho móvel.

O ser humano quando interage com a tecnologia, envolve nessa interação não só aspectos racionais, mas também emocionais como seu estado de espírito, humor e disposição, caracterizados por Ciborra (2006) como a situacionalidade. Assim, ao analisar o contexto, acredita-se que a situacionalidade do indivíduo, isto é, sua situação interna (mente e coração), e sua situação no mundo, contribui para entender a interação em ambientes ubíquos sem separar o indivíduo do seu mundo exterior. Além disso, a tecnologia oferece diferentes possibilidades de interação no momento do seu uso. Estas possibilidades vão influenciar o tipo de interação que vai emergir, e assim vão dar um significado para o contexto (SORENSEN, 2OIO).

Figura 2: Contexto em Ambientes Ubíquos de Trabalho Móvel

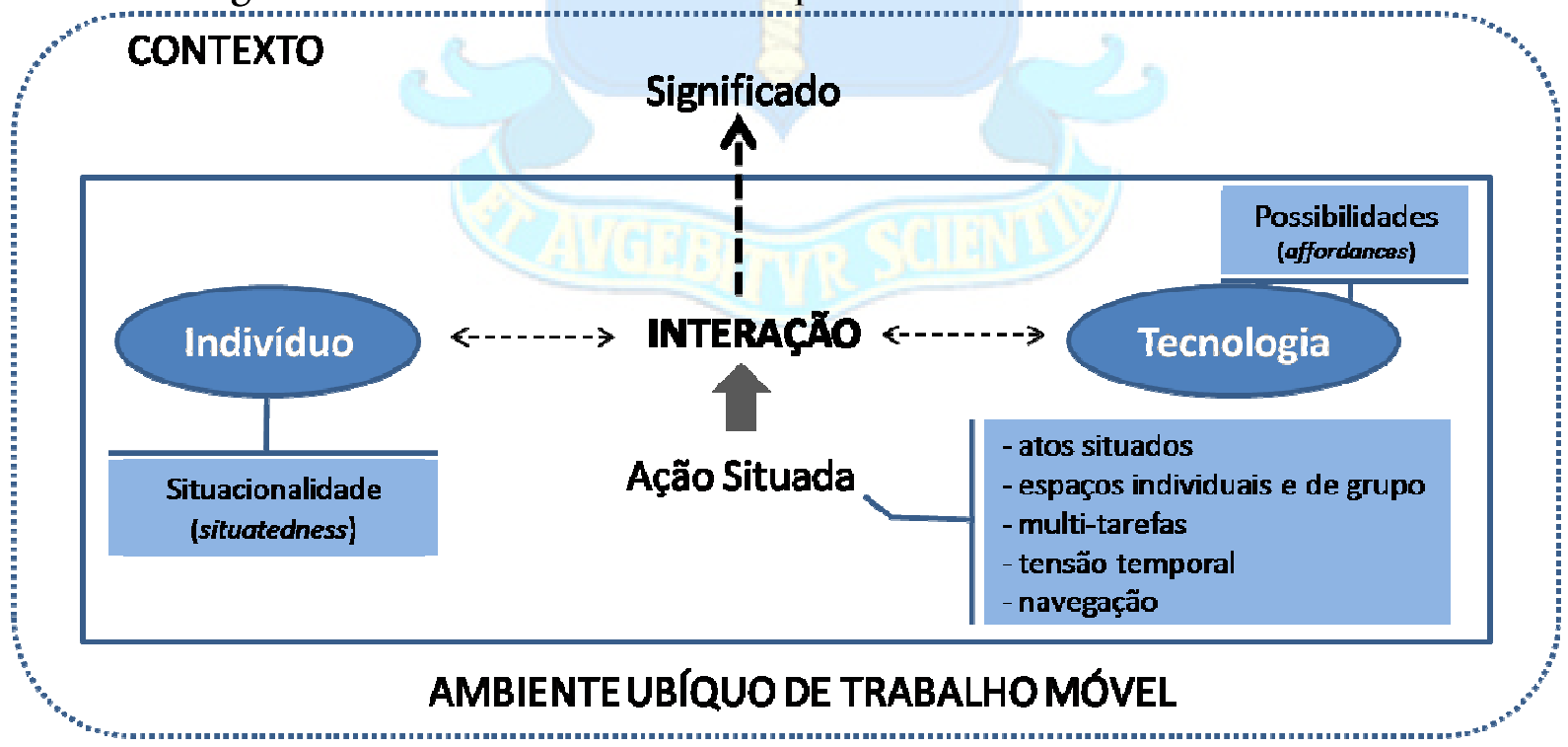

Fonte: Elaborado com base em Dourish (2004), Tamminem et al. (2004), Ciborra (2006) e Sorensen (2OIO). 
O contexto, portanto, é gerado pelo significado da interação social entre indivíduo e tecnologia, em que esta interação é influenciada pela ação situada em determinado momento, assim como pela situacionalidade do indivíduo (“o ser com o mundo”) e as possibilidades da tecnologia. A visão fenomenológica possibilita um melhor entendimento do contexto pois permite ver o indivíduo não apenas onde 'está', mas sim como 'age' e 'sente’ durante a interação ubíqua. Dessa forma, quando se adentra no campo da pesquisa em computação ubíqua e suas consequências sociais e organizacionais, o conceito de contexto sob o ponto de vista fenomenológico, ou seja, que traz consigo conceitos de interação, ação situada e situacionalidade sugere ser o mais adequado.

\section{Considerações Finais: implicações do entendimento de Contexto no Paradigma da Ubiquidade}

Entender o conceito de contexto no trabalho móvel à luz do paradigma da ubiquidade traz algumas implicações para os trabalhadores móveis, gestores, desenvolvedores de sistemas e organizações. O fato de a computação ubíqua ser transparente e onipresente demanda do indivíduo sua contínua disponibilidade em interagir. Assim, o trabalhador móvel com sua situacionalidade e escolhas das possibilidades tecnológicas, é que constrói o contexto ubíquo, isto é, a cada ação, a cada prática, está dando significado à sua interação com a tecnologia. Em função disso, práticas sociais de uso da tecnologia vão sendo criadas pelos trabalhadores móveis, muitas vezes sem que ocorra uma discussão ou consciência expressa de seu uso ou de suas decorrências.

Aos gestores que lideram trabalhadores móveis, usuários de ambientes ubíquos, cabe a compreensão das interações daqueles indivíduos, visto que eles estão constantemente criando significados da sua interação com a tecnologia. Sorensen (2OIO) destaca que na interação surgem preferências, propósitos e demandas pessoais do usuário em uma atividade em ambiente ubíquo. Desta forma, "relações adicionais e oportunidades emergem, como por exemplo, relativas à negociação das interdependências entre colegas distribuídos, mensuramento de desempenho, e o nível de discrição individual na tomada de decisão" (SORENSEN, 2OIO, p. 3). 
Do mesmo modo, para as organizações o entendimento do contexto como um processo de interação entre indivíduo e tecnologia implica em oferecer um suporte adequado a um novo tipo de arranjo que emerge da computação ubíqua, que é o trabalho colaborativo. No ambiente ubíquo o trabalho móvel colaborativo envolve diversos indivíduos, diversos aparatos tecnológicos (tela holográfica, vídeo, áudio, escrita), onde estes interagem e a cada ação situada, criam novos significados. Dessa maneira, uma infinidade de contextos pode emergir, demandando um suporte organizacional que permita o efetivo trabalho em colaboração.

Dey (200I) asseverava naquela época que um entendimento do contexto permitiria aos desenvolvedores de aplicações computacionais um apoio na determinação dos comportamentos conscientes ao contexto. Conforme Dourish (2004) a visão positivista de contexto possibilita responder aos problemas práticos de desenvolvedores de sistemas ubíquos, visto que eles buscam representar um determinado ambiente ou local que está tendo uma interação. Os desenvolvedores de sistemas quando incorporam as noções de contexto desejam que as tecnologias possam ser mais sensíveis aos detalhes de cenários específicos de uso, justamente o que os cientistas sociais criticam (DOURISH, 2004).

Nesse sentido, Dourish (2004, p. II) defende uma visão fenomenológica do contexto, assegurando que "o significado de uma tecnologia, não pode ser divorciado dos modos que as pessoas têm de usá-la”. Então, a maior dificuldade e desafio para desenvolvedores é a de reproduzir na tecnologia as novas formas de significado social que se dão nas práticas do dia a dia dos usuários, visto que a computação ubíqua apoia o processo em que o contexto é continuamente manifestado, definido, negociado e compartilhado (DOURISH, 2004). Segundo o autor são os usuários e não os desenvolvedores que determinam o significado das tecnologias que eles utilizam, através dos modos que eles as incorporam em suas práticas.

Tamminem et al. (2004, p. I35) corroboram nesse sentido que "para ser socialmente aceitável e útil, a tecnologia consciente ao contexto deve ser baseada em conhecimento empírico do contexto, analisado sob a perspectiva dos usuários finais”. Os autores apresentam os desafios ao lidar com o contexto para os desenvolvedores de sistemas ubíquos, e fazem sugestões de aspectos relevantes para atentar os 
desenvolvedores nas questões de ambientes de trabalho móvel. Dessa maneira, reconhecer, por exemplo, quando o indivíduo caminha, corre, aguarda, ou ainda, desenvolve atividades rotineiras, não rotineiras, quando se envolve com pessoas de convívio usual ou não usual, são exemplos de ações situadas que merecem atenção. Conhecer as características das ações situadas trazidas por Tamminem et al. (2004) permitiria um melhor entendimento das ações do indivíduo, momento a momento, de modo que, seja possível, capturar e customizar determinadas experiências para uso futuro nas aplicações ubíquas.

Ocorre que além da ação situada a cada interação, Ciborra (2006) nos lembra que o indivíduo carrega consigo todas suas emoções ao interagir com a tecnologia. Logo, as pessoas por meio de suas práticas vão buscar moldar o uso da tecnologia, e fazer adaptações no uso, de acordo com suas preferências, necessidades, desejos, estado emocional em geral, o que acarretará a exigência de novos desenhos de aplicações.

Portanto, a análise do conceito de contexto de forma dinâmica, o qual emerge da interação, e se dá por ações situadas abrangendo aspectos do indivíduo como um todo, implica que se torna difícil transpor todos os elementos envolvidos para um sistema ubíquo. Assim, o acompanhamento contínuo das interações entre indivíduo e tecnologia, poderia permitir, ainda que de forma incipiente, um melhor entendimento das possibilidades de contextos a serem construídos.

Por ser um novo paradigma, os efeitos e implicações da Computação Ubíqua ainda não são totalmente conhecidos e evidenciados. Entretanto, este artigo trouxe indícios das implicações do entendimento do contexto nas organizações, aos indivíduos, aos desenvolvedores, bem como na relação indivíduo-tecnologia. Na área de Sistemas de Informação e de Interação Homem-Computação, pouco esforço tem sido investido no entendimento das experiências dos indivíduos em ambientes de computação ubíqua (SORENSEN, 2OIO). Logo, o estudo da interação entre usuário e tecnologia nestes ambientes e a formação de contextos é um tema relevante a ser explorado pela academia.

\section{Referências}

ANDRIESSEN, E; VARTIAINEN, M. Emerging Mobile Virtual Work. In: ANDRIESSEN, E. VARTIAINEN, M (Eds.) Mobile Virtual Work: A New Paradigm? Heidelberg: Springer, 2006. 
BRASIL DIGITAL@INTEL. Trabalhadores móveis. Disponível em: http://blogs.intel.com/brasildigital/2008/o5/trabalhadores_moveis.php. Acesso em I2 de Junho de 2010 .

CASTELLS, M. Sociedade em Rede. São Paulo: Paz e Terra. Volume ı.8a Ed. 2005.

CIBORRA, C. The mind or the heart? It depends on the (definition of) situation. Journal of Information Technology, v. 2I, I29-I39, 2006.

COMPUTER WORLD. Acesso remoto é utilizado por 25\% das empresas no Brasil. Disponível em: http://computerworld.uol.com.br/gestao/2OIO/o5/o4/acesso-remoto-e-utilizado-por-25-dasempresas-no-brasil/. Acesso em oi de Julho de 20 oro.

COUTAZ, J.; CROWLEY, J. L.; DOBSON, S.; GARLAN, D. Context is Key. Communications of the $A C M$, v. 48, n. 3, March, 2005 .

DEY, A. K. Understanding and using context. Personal Ubiquitous Computing, v. 5, n. I, 4-7, 2 OOI.

DOURISH, P. What we talk about when we talk about context. Personal and Ubiquitous Computing, v. o8, n. I, p. I9-3O, 2004 .

FREIRE-MAIA, N. A ciência por dentro. Petrópolis: Vozes, I99I.

IDG NOW. Vendas de tablets "perderam o gás" em 2013, segundo IDC. Disponível em: http://idgnow.com.br/mobilidade/2OI4/OI/3I/vendas-de-tablets-aumentam-em-2OI3-masperdem-pique-dos-anos-anteriores/. Acesso em I5 Mar. 20I4.

KAKIHARA, M.; SORENSEN, C. Expanding the 'Mobility' Concept. ACM SIGGROUP Bulletin, N. 22, p. 33-37, 2OOI.

KAKIHARA, M.; SORENSEN, C. Mobility: an extended perspective. In: Proceedings of the Hawaï International Conference on System Sciences, 35, Big Island, Hawaii, IEEE, 2002.

KLEINROCK, L. Breaking loose. Communications of the ACM, v.44(9), p. 4I-45, $200 \mathrm{I}$.

KUHN, T. S. A estrutura das revoluções científicas. São Paulo: Editora Perspectiva, I982.

LYYTINEN, K.; YOO; Y. Research Commentary: The Next Wave of Nomadic Computing. Information Systems Research, v. I3, No. 4, pp. 377-380, 2002.

MYERS, A. et al. Taking Handeld Devices to the Next Level. IEEE Computer Society, December, p. $36-43,2004$.

PERRY, M.et al. Dealing with Mobility: Understanding Access Anytime, Anywhere. ACM Transactions on Computer-Human Interaction, v.8, n.4, p.323-347, $200 \mathrm{O}$.

ROUSSOS, G. Ubiquitous Computing for Electronic Business. In: ROUSSOS, G. (Ed.). Ubiquitous and Pervasive Commerce: New Frontiers for Electronic Business. Springer, 2006.

SACCOL, A.; REINHARD, N. Tecnologias de Informação Móveis, Sem Fio e Ubíquas: Definiçőes, Estado-da-Arte e Oportunidades de Pesquisa. Revista de Administração Contemporânea, 2007.

SHAMBARE, R.; RUGIMBANA, R.; ZHOWA, T. Are mobile phones the 2Ist century addiction? African Journal of Business Management. Vol. 6(2), pp. 573-577, $2 \mathrm{OI2}$.

SORENSEN, C. Cultivating Interaction Ubiquity at Work. The Information Society, v. 26, n. 4, pp. $276-287,2$ OIO. 
TAMMINEM, S.; OULASVIRTA, A.; TOISKALLIO, K.; KANKAINEN, A. Understanding mobile contexts. Personal and Ubiquitous Computing, 8: I35-I43, 2004.

TECNOLOGIA TERRA. Tráfego de dados em celulares e tablets cresceu 81\% em 2013. Disponível em: http://tecnologia.terra.com.br/trafego-de-dados-em-celulares-e-tablets-cresceu-8I-em20I3,ba997405856344IoVgnVCMiooooo98cceboaRCRD.html. Acesso em I5 Mar. 2014.

VARTIAINEN, M. Mobile Virtual Work - Concepts, Outcomes and Challenges. In: ANDRIESSEN, E; VARTIAINEN, M (Eds.) Mobile Virtual Work: A New Paradigm? Heidelberg: Springer, 2006.

YUAN, Y.; ZHENG, W. Mobile task characteristics and the needs for mobile work support: A comparison between mobile knowledge workers and field workers. Eighth International Conference on Mobile Business. ICMB, pp.7-II, June/July, 2009.

WEISER, M. The computer for the 2Ist century. Scientific American, v. 265(3), 94-IO4, I99I.

WEISER, M.; GOLD, R.; BROWN, S. The origins of ubiquitous computing research at PARC in the late i98os. IBM Systems.Journal, I999.

ZHANG, J.; YUAN, Y. M-commerce versus Internet-based E-commerce: The key differences.

Proceedings of The Americas Conference on Information Systems, v. 8, p. I892-I9OI, 2002.

ZHENG, W.; YUAN, Y. Identifying the differences between stationary office support and mobile work support: a conceptual framework. Int. J. Mobile Communications, v. 5, No. I, pp.IO7-I22, 2007. 